\title{
9
}

\section{Multi-level Governance in Aboriginal Community Development: Structures, Processes and Skills for Working across Boundaries}

\author{
Wendy Jarvie and Jenny Stewart
}

\section{Introduction}

As a federal nation, Australia has had long experience with multi-level governance (MLG). In most policy fields, federal and state governments share powers, producing complex and often intricate intergovernmental structures and processes (Galligan et al. 1991; Painter 1998). As policy and management challenges have grown in complexity, interest has increased in finding new ways of working that transcend these traditional arrangements (Edwards and Langford 2002). 'Working across boundaries' represents an emergent form of MLG, as policymakers have sought to address the challenges of complex, fluid and overlapping jurisdictions (Bache and Flinders 2004: 5).

Policymaking for Indigenous Australians exemplifies these challenges to a high degree. The failure of governments to work together and with communities has, arguably, been a fundamental factor in producing poor outcomes and mutual frustration. During the early 2000s, the government 
under Prime Minister John Howard, in its third term of office, decided that the status quo was not an option and a 'quiet revolution' was needed (Vanstone 2005). Together with the states and territories, they decided to trial new ways of working to tackle Indigenous disadvantage. The results were the Council of Australian Governments (COAG) trials of 2003-07, which were an attempt by governments (state, federal and local) to embrace the possibilities of cross-boundary working, and to learn from the results: a practical experiment in MLG in the Australian context.

In this chapter, we focus on the structures, processes and skills that were deployed and developed in the most successful COAG trial site, in the Murdi Paaki region of western New South Wales (ANAO 2008). Our aim is to elucidate the ways in which actors (particularly government and community actors) addressed the challenges of cross-boundary working in an environment of considerable jurisdictional flux and ambiguity, and to identify, from the case study, some guiding principles for bureaucratic action.

\section{Background}

Improving outcomes for Indigenous Australians has long been considered one of the most difficult problems in Australian public policy. On most indicators of wellbeing, Aboriginal people continue to lag significantly behind the rest of the Australian population, although, in recent years, the gap has narrowed in relation to some indicators (SCRGSP 2016).

The policy context is generally considered to be complex, conflicted and multi-layered. Policy values have oscillated dramatically over the past 40 years, reflecting the outcomes of fierce ideological battles, the actions and efforts of activists and (often) the consequences of disappointing experience.

Within this environment of swirling contestation, there have been, beginning in the mid-1990s and gathering strength in the 2000s, a number of attempts by governments to approach these difficult problems in new ways, and to learn from the resulting experience. Many of these new approaches emanated from COAG and included an increasing emphasis on intra-governmental cooperation and on partnerships between Aboriginal people and governments (see COAG 2004; Gray and Sanders 2006). 
In 2002, COAG announced trials of these new approaches at eight sites across Australia, one in each state and territory (COAG 2002). Murdi Paaki was the site chosen for New South Wales.

The Murdi Paaki region was a governance region under the Aboriginal and Torres Strait Islander Commission Act 1989. It included 16 communities ranging from Broken Hill, Wilcannia, Menindee, Dareton-Wentworth and Ivanhoe in the south-west, to Brewarrina, Bourke, Lightning Ridge, and Walgett in the north and Cobar in the centre. Gullargambone, Collarenebri, Goodooga, Enngonia, Weilmoringle and Coonamble completed the set.

In 2005, the Indigenous Australian population of Murdi Paaki was around 7,500 people, representing 14 per cent of the total population of the region. The region is the most disadvantaged in New South Wales, with significant problems of health, employment, housing, education and crime. At the time of the trial, these were exacerbated by a long period of drought with few agricultural jobs, and flow-on impacts on villages and towns. Further detail is in Jarvie and Stewart (2011).

\section{Design features}

Type II MLG is characterised by fluidity, often manifesting as a patchwork of overlapping jurisdictions, arising in response to particular governance challenges (Kay; Hooghe and Marks 2003). While the COAG trials exhibited many of these features, it is important to acknowledge that, at least in their initial forms, they were acts of deliberate administrative creation, rather than emergent forms of activity. The trial objectives included tailoring government action to identified community needs and aspirations, encouraging innovation, cutting red tape, working to build the capacity of Aboriginal people so that they could negotiate as genuine partners with government, building the capacity of government employees so they could work in the new way with Indigenous communities, and the negotiation of agreed outcomes and benchmarks for measuring progress (Morgan Disney 2006). These design features provided an institutional underpinning (and impetus) to the cross-jurisdictional framework for governance. 


\section{Lead agencies}

For each trial site there was a lead Commonwealth agency and a lead state government agency that were expected to liaise and coordinate with relevant agencies within their jurisdictions, as well as with their state counterparts and the Aboriginal communities. In Murdi Paaki, the lead Commonwealth agency was the Department of Education, Science and Training (DEST), and the NSW Department of Education and Training (DET) was the lead for the NSW Government.

\section{Shared responsibility agreements in Murdi Paaki}

Shared responsibility agreements, at both community and regional level, represented a key part of the original program logic because they established a basis for mutual commitments to outcomes. They were particularly prominent in the Murdi Paaki context. In 2003, a shared responsibility agreement was signed between the Commonwealth Government (represented by DEST), the NSW Government (represented by DET) and the Murdi Paaki Regional Council. This document established regional objectives to be addressed by partnership-based working arrangements. As well as this overarching agreement, agreements were signed in relation to a number of specific activities. In all, 29 shared responsibility agreements were signed across the region

\section{Flexible funding}

Significant staff and project-funding resources were needed, and creative approaches to financing by participating agencies were required. Because projects were to be identified by communities, and could cross existing government and program boundaries, flexible funding arrangements were necessary to support them. Within the Commonwealth, the Office of Indigenous Policy Coordination in the Department of Immigration and Indigenous Affairs (DIMIA) set up a flexible funding pool to support all the COAG sites, and lead agencies could bid for funds. To increase the speed of finding funds for Murdi Paaki, the Minister for DEST, Brendan Nelson, agreed in 2003 for uncommitted funds from the Indigenous Education Strategies program to be set aside to meet education elements of projects. Later in 2006-07, DEST established a fund that drew from across the department as a whole. 
Actual delivery and funding of projects was undertaken by a number of different agencies. For example, funding of consultants to help to develop the action plans was provided by Family and Community Services (FaCS), while secretariat support for the working parties was funded from the Department of Employment and Workplace Relations' (DEWR) Indigenous programs, with training provided by NSW TAFE. Facilitators were funded by the NSW Premier's Department, the Commonwealth's flexible funding pool and DEST. The Commonwealth Department of Health and Ageing (DOHA) funded a drug and alcohol network. In reality, the bulk of the funding was found by the Commonwealth, particularly DEST, who not only funded four staff positions for Aboriginal officers in Dubbo and a support section in Canberra, but contributed an estimated $\$ 2.1$ million to projects funded under shared-responsibility agreements.

\section{Structures}

Structures are important in MLG because they provide occasions, arenas and spaces for interaction. In the Murdi Paaki trial, the sheer number of actors required structures that transcended 'top-down' and horizontal divides and were robust enough to be enduring and meaningful but were also sufficiently flexible to give participants room to move.

\section{Intergovernmental networks}

Within the Commonwealth Government, the key agencies were the lead agency, DEST, FaCS, Families, Community Services and Indigenous Affairs (FaCSIA) after 2005, and the Aboriginal and Torres Strait Islander Services (ATSIS) (2003-04). Later, DOHA became a significant player at a project level. Within DEST, officers engaged in supporting the trial were located in Canberra, Sydney and Dubbo, and the complex information flows and coordinated action were managed through the formation of a Murdi Paaki Coordination Group. Because state managers of Australian Government departments were responsible for Commonwealth service delivery in New South Wales, these officers were actively engaged as well. In addition, the Secretary of DEST was a member of a Commonwealth Government committee composed of the Secretaries from the lead agencies of the eight trials, as well as the head of Prime Minister and Cabinet and ATSIS. ${ }^{1}$

1 A detailed description of the arrangements of the Commonwealth secretaries, and how this changed over time, can be found in Gray and Sanders (2006), p. 5. 
From the NSW Government side, key players were DET (the lead agency), the NSW Department of Aboriginal Affairs (DAA), and the NSW Premier's Department. DEST, DET and DAA provided officers for the action team, which was located in Dubbo. DET used the existing NSW Government Regional Coordination Management Group to coordinate across NSW Government agencies. The NSW Government had a stable Indigenous Australian engagement philosophy - Two Ways Together ${ }^{2}$ - over the course of the trial, which enabled them to engage in a steady and systematic way with Murdi Paaki, although, like many state governments, they had limited flexible funding to contribute to community priorities. Local government was not a significant player in the trial, except in a couple of communities.

In addition, there were a large number of organisations that engaged in different ways and at different times over the trial, including the Barwon Darling Alliance, various chambers of commerce, Aboriginal organisations, such as land councils, medical services, community development employment projects, and the Murdi Paaki Regional Enterprise Corporation.

\section{Government-community networks}

The action team was the focus of day-to-day interaction between government and community and their experience on the ground gave them the insight to be the most critical officials. Meetings involving higher levels of government opened with reports from the action team and, indeed, discussions and decision-making were characterised by lack of hierarchy - no single agency controlled the agenda; it was set mutually. Overall guidance for the trial was provided by a joint community, NSW Government and Commonwealth Government steering committee. The chair was rotated between the three lead partners - Sam Jeffries as the chair of the Regional Council and then the Murdi Paaki Regional Assembly, and deputy secretaries from DEST and DET. The committee met regularly, no less than four to five times a year to the end of 2007, generally in Sydney but also, when it could be organised, within the region. Four regional thematic subgroups were developed late in the trial: education and employment, culture and heritage, health, and crime and justice. Developed in response to the 16 community working party action

2 Two Ways Together - Partnerships: a new way of doing business with Aboriginal people, NSW Aboriginal Affairs Plan 2003-12. See NSW Auditor-General (2011). 
plans and the realisation that many priorities were best handled through a regional approach, subgroups included representatives of Aboriginal communities and Commonwealth and NSW government agencies.

The action team in Dubbo ensured that the communities were the focus of action and attention. Supporting a simple interface, however, required a high level of government complexity. As one interviewee explained 'this level of complexity was needed to produce simplicity on the ground'. Figure 9.1 shows some of the key Murdi Paaki communication and coordination structures as they existed in 2006.

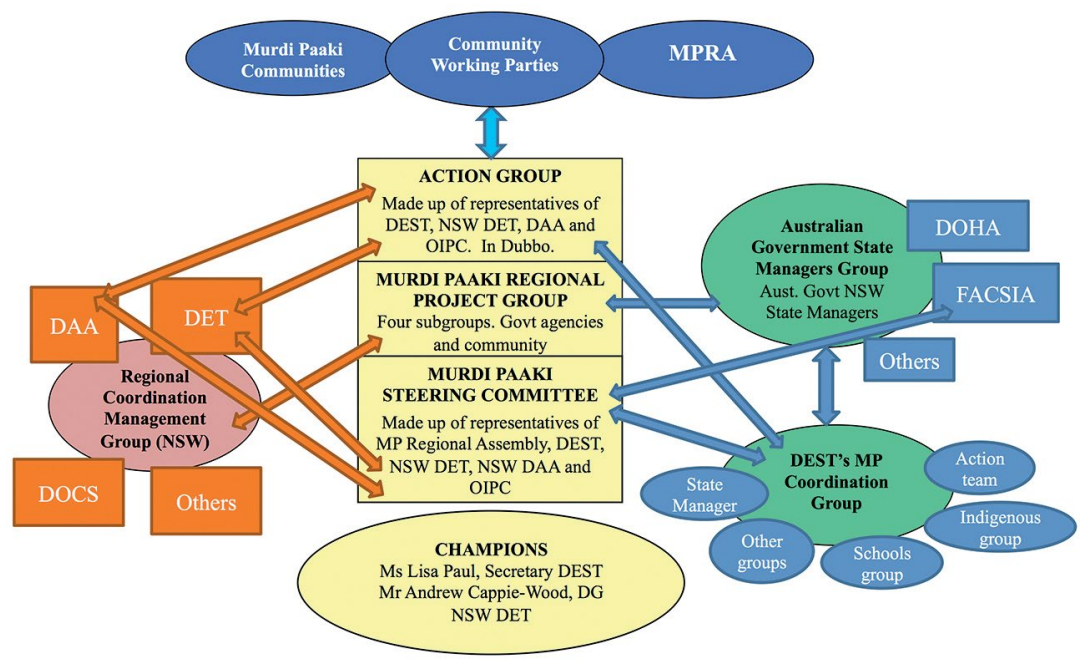

Figure 9.1: Bureaucratic complexity: Murdi Paaki governance structures 2006

Source: Wendy Jarvie and Jenny Stewart

\section{Community}

Two main structures within the Aboriginal community engaged with government through the trial. The first, the Murdi Paaki Regional Assembly - a new form of the previous Murdi Paaki Regional Council proved to be a significant actor. Chaired by Indigenous Australian leader, Sam Jeffries, and meeting regularly throughout the period, the assembly comprised the chair together with chairs of 16 Murdi Paaki community working parties. At its meetings, the assembly discussed priorities, progress and plans for the region as a whole. It was also a prime point of contact for government agencies (state and federal) to interact with the communities. 
The second was the community working parties. Formed under the auspices of the regional council in the late 1990s, their prime role was then to coordinate action in relation to housing. In the Murdi Paaki trial, these working parties were refreshed and/or created and acted as the key intersection point between the action team, agencies and the communities themselves. Each working party was constructed differently and reflected the characteristics of the local community, although they worked under a common operational framework. The working parties were not formal corporate bodies and membership was open to everyone in the Indigenous community in each town. Leadership was determined by a voting process or, in the smaller communities, more informally. In practice, the majority of chairs were men although, over time, a larger number of women began to assume leadership roles.

\section{Processes}

Peters and Pierre (2004) stress that, whatever the degree to which its analysis is institutionally directed, MLG is fundamentally about process. As they put it, 'multi-level governance refers to connected processes of governance incorporating both public and private actors in contextually defined forms of exchange and collaboration' (Peters and Pierre 2004: 76). It follows, therefore, that managing MLG requires attention, not just to structures, but also to the ways in which these structures are articulated through inter-agency and interpersonal relationships. In the next section we detail the processes that built and maintained these relationships.

\section{Negotiation}

Continuous negotiation, though not emphasised in the original trial documents, turned out to be at the heart of the COAG trials. Effective partnership between governments required constant negotiation particularly around galvanising resources, but also to join up government agencies' action, such as in health or education, and to ensure they were adopting the same approach. Partnership with Aboriginal communities also required intense negotiation - particularly in identifying community priorities and methods of project financing and management, as well as in the precise wording of shared responsibility agreements. Indeed, as the Murdi Paaki case makes clear, the process of negotiation was an important mechanism for building trust and for developing a common 
understanding of issues and the best way to address them. In most locations there were also intensive negotiations, if not disputes, between Aboriginal community members, families and clans as they identified priorities and jockeyed for influence with governments.

Where the negotiations were successful, projects could be identified and presented to government. Where unsuccessful, paralysis set in. When dysfunction set in in Bourke, the action team held firm and rejected offers to make deals outside the community working party. Some Bourke community members saw that this assisted their existing leadership to re-establish consensus. Indeed, for some community members, the working party and the governance it represented were important disciplines in themselves: 'Proposals had to come before the working party - there were no separate deals.'

\section{Planning}

Given the importance of working to address community priorities, the steering committee agreed that each community working party would be supported to develop an action plan. These set out the community vision and priority actions for dealing with particular problems. The majority of action plans were completed in 2005, but a number were not finalised until May 2006, when the trial had only 18 months left to run. Given concern over government impatience with progress, the steering committee agreed to try to develop some shared responsibility agreements with the most advanced communities. The first agreements with Bourke and Brewarrina were signed in December 2004, two years into the trial but before the action plan for Brewarrina was finalised. It was soon found that communities were struggling to relate to government and, in late 2005, facilitators were recruited to provide professional and technical help for the communities.

\section{Building trust}

Trust with Aboriginal communities was built through keeping commitments, continuous engagement and negotiation. The continuous engagement was important as it showed that public servants were listening seriously and were prepared to enter into debate, rather than make

3 Bourke community member interviewee. 
arbitrary decisions. They didn't always satisfy community expectations, but they were prepared to spend time to get an outcome everyone was happy with. This was very different from the kind of 'consultation' in which government officials listen politely and then leave. A particularly important feature was the preparedness of the action team to support small projects that built Aboriginal culture, such as the refurbishment of a cemetery or the holding of a culturally significant festival. But it required a cultural change: 'We had to leave our ego at the door if we wanted to engage with the communities ... Also to build trust with NSW (government), we had to avoid the stereotype that we were the heavy handed Commonwealth, using our money to bully.' ${ }^{3}$

\section{Supporting community governance}

Particularly important were the six-monthly governance workshops for the chairs of community working parties and secretariats, mentoring for chairs and a youth leadership program. Where communities were fractured, the Dubbo-based action team attempted to help them move forward by 'refreshing' the membership of the community working party. The working parties were supported by paid secretaries and, from 2005, by facilitators who played a brokerage role, progressing matters between meetings and engaging with other groups in order to advance particular projects.

\section{Prioritising}

Community priorities were identified in the 16 community action plans and supported through shared responsibility agreements, occasionally involving local government as well as state and Commonwealth governments. Local agreements covered environmental health, community and family wellbeing, the engagement of young people in community life and education, and crime prevention (Urbis Keys Young 2006). For example, these agreements supported a night patrol, a culturally significant festival and early childhood education (Bourke); an oval (Enngonia); refurbishing a cemetery (Collarenebri); and supporting Aboriginal community-controlled organisations and agedcare provision (Brewarrina).

4 DEST public servant interviewee. 
Regional priorities were developed by the Murdi Paaki Regional Assembly or the regional subgroups, and included professional technical support; air conditioning in homes; health, education and employment; crime; community capacity and leadership; and regional cultural and heritage. These were frequently responded to through regional shared responsibility agreements. A particular subset of this was government-led initiatives that were derived from community or assembly priorities but not funded through formal agreements with the assembly or communities. Two examples are from education and health:

1. The Learning to Read, Reading to Learn initiative (Koop 2008) This program was the major contributor to the rapidly rising literacy scores in Murdi Paaki that occurred during the trial (Jarvie 2008). It was supported by strategies such as school principals discussing the school plan with the local community working party, a mentoring program for school principals and workshops and conferences for principals and schools under the Commonwealth Government 'Dare to Lead' program. The agreement reached between the federal department and its NSW partner was critical here, with DEST supplying the funds from its flexible funding bucket.

2. The Drug and Alcohol network

The NSW Health Department, working with Commonwealth Government support and funding, was able to develop a number of useful health strategies, with the federal department drawing on its experience working in communities in Queensland. A systematic approach was adopted, with a consultant scrutinising community action plans for health-related priorities and validating findings through discussion with 10 communities. Five key themes were identified, including mental health and substance abuse, youth issues, chronic disease, family wellbeing and environmental health. A partnership between the Commonwealth Office of Aboriginal and Torres Strait Island Health (part of DOHA), the Greater Western Area Health Service, the Outback Division of General Practice, the Royal Flying Doctor Service and The Lyndon Community in Orange was created, and funding, including $\$ 1.22$ million recurrent funding from DOHA, was found to establish a drug and alcohol network. The network, based on partnership principles of the trial, has heavy engagement with Aboriginal medical services, community working parties and regular reporting to the Regional Assembly. 


\section{Skills}

The 'people side' of MLG is insufficiently appreciated. Skills are not only demanded - they are also developed through this way of working. From the perspective of Indigenous Australian leadership, the most important outcome was their personal development, in particular the growth of skills and confidence, not only in dealing with government, but also in engaging with other Aboriginal leaders and within their own community. ${ }^{5}$ The 2006 evaluation (Urbis Keys Young 2006: ii) identified that governance capacity had improved and continues to improve and that communities 'appear better able to articulate their priorities to government in constructive fashion'. Interviewees noted the increased visibility of Aboriginal people in some communities, such as Cobar. For many of the smaller communities, this was the first time they felt they 'had a voice' and government attention, which also contributed to their confidence.

One of the unexpected successes of the Murdi Paaki trial was the releasing of bureaucratic energy. The high-level impetus and flexible structure of the trial enabled public servants to carry out work that they would otherwise have found difficult to get support for and to fund, as exemplified by the education and health initiatives. The public servants involved in those projects, when interviewed in 2010, retained strong memories of the sense of opportunity and excitement of the time. Bureaucratic energy and initiative was liberated by the trial, which was a result of support 'from the top' and flexible ways of working that the trial legitimated. A number of Indigenous Australian members of the Dubbo staff also thought that it was the best job they had ever had. They appreciated the autonomy and the responsibility: 'I knew when I said I would do something I would have to do it. I knew I would be going back to the community.' In some ways, the impact on the public servants involved in the education and health departments remains one of the most sustained outcomes of the Murdi Paaki trial.

5 Feedback from meeting with Murdi Paaki Regional Assembly October 2009. 


\section{Leadership}

The importance of leadership in individual communities has already been mentioned. The leadership provided by Sam Jeffries was also critical, not only in his pragmatic support to continue the trial despite the abolition of the Aboriginal and Torres Strait Islander Commission in 2005 but also his work to create the Regional Assembly, which provided an essential infrastructure for capacity-building and negotiation with government (Jeffries \& Menham 2011). There are few regions in Australia where leadership by Indigenous Australians is so relatively uncontested, or so effective.

Leadership in government was important as well. It was leadership that focused on providing structure and support for those 'on the ground' in a way that was appropriate for the design of the trial. This meant communicating the necessity for role flexibility. As one senior public servant said: 'Everyone was a leader at times, a partner at times and a follower at times.' The calibre of the leaders of the action team and the continuity of the team's personnel was a significant ingredient, as their role required consistent engagement and negotiation with Aboriginal communities and with government officials of many agencies and at all levels. Public servants saw the culture and leadership of the government agencies as critical - 'everyone respected each other, despite our differences'; 'we had a principle - to deliver on all commitments' and 'we knew we had support from the top'.

When negotiating with communities, collaborative leadership could be difficult for public servants who were used to assuming control and dispensing money from defined sources. Already divided communities could be further fractured in the face of the more traditional bureaucratic approach.

\section{Listening}

All actions were underpinned by the need to build and maintain trust and this necessity permeated everything governments did. If there was no trust between governments, and between Aboriginal communities and government, the trial would fail. The first essential was learning how to listen. 'Stop talking and start listening' was the first request made by Indigenous Australian leaders at a meeting in 2003. Delivering early on 
some small but important projects, such as a community garden and a cemetery makeover, was important, as was delivering on commitments, including holding to agreed processes, despite occasional setbacks.

\section{Joining up the dots}

Bureaucratic (and community) silos mean that people who should be communicating with each other frequently do not. Successful community brokers recognise these informational blockages and do something about them - 'joining up the dots', as one experienced broker termed the process. Joining up the dots also meant identifying opportunities as they emerged, and working with events as they happened, rather than trying to engineer outcomes. This 'administrative bricolage' saw the Bourke facilitator use an emergent crisis about juvenile crime to further the community's case for improved holiday programs and after-school care.

\section{Obstacles and challenges}

The bureaucratic politics of MLG are incessant and exigent. Change is inevitable and is often the result of impatience with the slowness of transaction-intensive policymaking. If MLG is not only an inevitable and desirable phenomenon, these obstacles (which derive from friction points with more conventional ways of working) require attention.

\section{Instability in the authorising environment}

The COAG trials were to last five years, which is a relatively long time by Commonwealth Government standards. There was, however, considerable turbulence in the Commonwealth policy environment. First, in July 2003, the Aboriginal and Torres Strait Island Commission's (ATSIC) program functions were dispersed to mainstream government agencies and its coordination role was handed to ATSIS, a new executive agency in the immigration and multicultural affairs portfolio. This was followed in 2004 by the abolition of ATSIS and the absorption of its functions into DIMIA, and the announcement that Commonwealth Indigenous programs would be coordinated on the ground from 29 Indigenous Coordination Centres. The abolition of ATSIC, including the ATSIC regional councils, followed in 2005 and, in January 2006, Indigenous policy coordination was transferred to the expanded FaCSIA. Finally, 
in 2007, in the last year of the trials, the Commonwealth Government announced the Northern Territory emergency intervention, which was a major practical and philosophic shift away from partnership with Aboriginal communities to direct action and control.

Meanwhile, in late 2005, six of the eight Commonwealth departmental secretaries relinquished their lead agency roles to the Office of Indigenous Policy Coordination, part of DIMIA and, later, FaCSIA. Many had found progress in negotiating with Aboriginal communities to be slow and some of the problems intractable (Gray and Sanders 2006). The Commonwealth was also negotiating bilateral agreements with state governments that, in some states, subsumed the trial activities. In many trials, the handover of leadership within the Commonwealth to the Office of Indigenous Policy Coordination in 2005 led to the effective end of the trial as the approach was merged into new delivery arrangements through the Indigenous Coordination Centres. When Commonwealth interest in the trials waned and resources dried up, with few exceptions, state agencies also lost focus. An evaluation was published in 2006 but, by then, activity had ceased.

\section{Instability in communities}

The community working parties that we examined in detail found the work of consensus-formation and action planning to be extremely difficult. The work was demanding and time-consuming and required considerable diplomatic skills to overcome divisions in the community. All the working parties had periods of instability, and one withdrew from the trial for a period. Six of the working parties did not sign shared-responsibility agreements during the trial, apart from the regional agreements. Personalities and leadership factors played a key role here. Family-based factions formed in several communities and there was competition for power and resources that swirled in and around the community working parties. Governments and the action team faced difficulties in this situation. There were no obvious tools that they could use to help, apart from refreshing the working party membership or supporting the facilitators and the chair to find a way through. 


\section{Working 'under the political radar'}

As instability in the Commonwealth policy framework increased, senior bureaucrats in DEST and DET agreed that they would try and work 'under the political radar' to keep faith with the original aims of the trials, and the Aboriginal leadership in Murdi Paaki. Indeed, they saw that any change in approach would undermine the level of trust they had built up with the Regional Assembly and Sam Jeffries. Relationships remained good between DET and DEST, so much so that officials who were only engaged at the end of the trial took the good relationship as a given. But working 'under the radar' has its risks for public servants because maintaining good relationships with the hierarchy remains essential.

\section{Coordination}

The original (and emergent) intergovernmental design was based on networking. The Howard Government and FaCSIA, however, were intent on a harder-edged approach. Announced in 2004, Indigenous Coordination Centres were supposed to achieve formal coordination of Commonwealth Indigenous programs at a regional level. As already described, most of the Commonwealth secretaries eventually handed their lead responsibilities to the Office of Indigenous Policy Coordination. This did not happen in Murdi Paaki, as Sam Jeffries made it clear that the Aboriginal communities wanted DEST and DET to stay involved in the trial. This complex situation was nominally solved by making the head of the Bourke Indigenous Coordination Centre a member of the action team and requiring all shared-responsibility agreements to continue to be approved by the Murdi Paaki steering committee.

With the transfer of Indigenous policy coordination to FaCSIA in 2006, the trial entered an extremely difficult phase. The manager of the Indigenous Coordination Centre was in the uncomfortable position of reporting to his own hierarchy, with its priorities and philosophy of Indigenous coordination, while another Commonwealth agency was leading the trial. This might have worked if everyone supported the philosophies and principles of the trial, however, the FaCSIA minister, Mal Brough, was promoting the government's belief in the efficacy of a more directive approach to Indigenous Australian development. Unlike the previous minister for Indigenous affairs, Amanda Vanstone, his approach was less consensual and more 'carrot and stick'. Brough wanted shared-responsibility agreements with individuals and clans, not 
communities. Indeed, by 2005, the emphasis in these agreements changed from partnership, to 'the community meeting its obligations' in return for government funding.

This philosophic approach better suited FaCSIA officials, who found the 'community-led' approach to priority setting in the Murdi Paaki trial to be too slow and too engaged with developing representative structures and not enough on delivering outcomes (Stewart and Jarvie 2015). For the last two years of the trial, much lead agency time and energy was spent negotiating with FaCSIA. Two particularly difficult items were finding ongoing support for the Regional Assembly (seen by FaCSIA as a representative structure that was not focused on outcomes) and the fact that the 2006 independent evaluation of the Murdi Paaki trial was seen by FaCSIA officials as exaggerating its achievements. From a DEST official's perspective, the philosophic differences were one of the biggest hurdles the trial faced and an important cause of the lack of sustainability of some aspects.

\section{Resources}

The additional cost of the trials, beyond normal government expenditure, is not known. By mid-2005, however, it was clear that the simple concept behind the trials was, when put into practice, costing more in time, resources and effort than had ever been envisaged by the COAG architects in 2002. Continuous negotiation was time-intensive and staff in Dubbo were stretched meeting its demands. The aim was to have a member of the Dubbo team at every community working party monthly meeting. This involved attendance at 16 monthly meetings spread across thousands of kilometres. This was in addition to assisting with working party problems, negotiating projects with communities and funding agencies, briefing hierarchy and organising six-monthly governance workshops and consultations with the Regional Assembly. Justifying these costs in terms of hard outcomes was a difficult task.

\section{Conclusion}

There is no manual for public servants operating in environments where achieving objectives requires working in cooperative, non-hierarchical ways. New public management, with its emphasis on outputs and outcomes, provides little guidance. The Murdi Paaki experience suggests a number of 'do's' that bear repeating here: 
1. build trust

2. start small

3. be flexible

4. negotiate

5. develop collaborative leadership

6. allow time to pass.

More broadly, the Murdi Paaki trial showed that governments find it difficult to sustain working in 'light touch' ways, particularly in a contested policy space such as Indigenous Australian development and in situations where there is a lack of cohesion. Public servants and ministers, impatient for outcomes in the key areas of measurable disadvantage - education, health and crime - have little patience with actions that are not, to them, directly linked to those outcomes, such as maintenance of cultural heritage, visibility in a community and having structures that enable their voice to be heard. Trust requires action and communication - through explanation, argument and negotiation. This is easy to characterise as time wasting.

The COAG trials suggest that MLG, to be successful in Indigenous Australian development, requires acceptance by community, governments, business, media and public servants that the focus on 'getting things done' must be moderated to include actions associated with building trust and creating consensus, including ensuring the stability of philosophy and policy, allowing sufficient time and valuing public servants who can embrace and undertake this new way of working.

\section{References}

ANAO (2008). Whole of Government Indigenous Service Delivery Arrangements. Performance Audit, Report no. 10. Australian National Audit Office, Canberra.

Bache, I. \& Flinders, M. (2004). Themes and Issues in Multilevel Governance. In: Bache, I. \& Flinders, M. (eds) Multilevel Governance. Oxford University Press, pp. 1-14. doi.org/ $10.1093 / 0199259259.003 .0001$ 
COAG (2002). COAG Reconciliation Framework: Report on Progress in 2001, Council of Australian Governments, webarchive.nla.gov.au/ gov/20070829162314/http://coag.gov.au/meetings/050402/index. htm

- - (2004). National Framework of Principles for Delivering Services to Indigenous Australians. Council of Australian Governments, Canberra.

Edwards, M. \& Langford, J. (2002). New Players, Partners and Processes: A Public Sector without Boundaries? National Institute for Governance, Canberra.

Galligan, G., Hughes, O. \& Walsh, C. (eds) (1991). Intergovernmental Relations and Public Policy. Allen and Unwin, North Sydney.

Gray, W. \& Sanders, W.G. (2006). Views from the Top of the 'Quiet Revolution': Secretarial Perspectives on the New Arrangements in Indigenous Affairs. CAEPR Discussion Paper No. 282/2006, ANU, Canberra.

Hooghe, L. \& Marks, G. (2003). Unraveling the Central State, But How? Types of Multi-level Governance. American Political Science Review, 97(2): 233-43.

Jarvie, W. (2008). Working Differently to Make a Difference in Indigenous Communities. Public Administration Today, 14(Jan-Mar): 5-12.

Jarvie, W. \& Stewart, J. (2011). Working with Complexity: Murdi Paaki and the COAG Trial 2002-2007. Australian Journal of Public Administration, 70(3): 259-74. doi.org/10.1111/j.14678500.2011.00734.x

Jeffries, S. \& Menham, G. (2011). 'The Murdi Paaki Regional Assembly and Government Reform', Journal of Indigenous Policy, 46: 41-45, www.austlii.edu.au/au/journals/JlIndigP/2011/9.html

Koop, C. (2008). Reading to Learn in Murdi Paaki: Changing outcomes for indigenous students. Literacy Learning: the Middle Years, 16(1): $41-46$.

Morgan Disney (2006). Synopsis Review of the COAG Trial Evaluations: Report to the Office of Indigenous Policy Coordination. Morgan Disney and Associates, November. 
NSW Auditor-General (2011). Performance Audit. Two Ways Together - NSW Aboriginal Affairs Plan, www.audit.nsw.gov.au/ ArticleDocuments/143/213_Two_Way_Together_Aboriginal_ Affairs.pdf.aspx?Embed=Y [Accessed: 17/12/2014].

NSW Government (2006). Two Ways Together Regional Report: Murdi Paaki. Department of Aboriginal Affairs, Sydney.

Painter, M. (1998). Collaborative Federalism: Economic Reform in Australia in the 1990s. Cambridge University Press, Melbourne. doi.org/ $10.1017 / \mathrm{CBO} 9780511552236$

Peters, B.J. \& Pierre, J. (2004). Multi-level Governance and Democracy: A 'Faustian bargain'? In: Bache, I. \& Flinders, M. (eds) Multilevel Governance. Oxford University Press, pp. 75-89. doi. org/10.1093/0199259259.003.0005

SCRGSP (2016). Overcoming Indigenous Disadvantage: Key Indicators 2016. Steering Committee for the Review of Government Service Provision, Productivity Commission, Canberra.

Stewart, J. \& Jarvie, W. (2015). Haven't We Been This Way Before? Evaluation and the Impediments to Policy Learning. Australian Journal of Public Administration. 74(2): 114-27. doi.org/10.1111/ 1467-8500.12140

Urbis Keys Young (2006). Evaluation of the Murdi Paaki COAG Trial. Prepared for the Office of Indigenous Policy Coordination, www.dss.gov.au/sites/default/files/documents/05_2012/coag_nsw.pdf [Accessed 21/12/2014].

Vanstone, A. (2005). Address to the National Press Club. 23 February, www.kooriweb.org/foley/news/vanstone1.html [Accessed: 02/06/2014]. 
This text is taken from Multi-level Governance: Conceptual challenges and case studies from Australia, edited by Katherine A. Daniell and Adrian Kay, published 2017 by ANU Press, The Australian National University, Canberra, Australia.

dx.doi.org/10.22459/MG.11.2017.09 